\title{
Insights into the Geobacillus stearothermophilus species based on phylogenomic principles
}

\author{
S. A. Burgess ${ }^{1,4^{*}}$, S. H. Flint ${ }^{1}$, D. Lindsay ${ }^{2}$, M. P. Cox ${ }^{3}$ and P. J. Biggs $s^{3,4^{*}}$
}

\begin{abstract}
Background: The genus Geobacillus comprises bacteria that are Gram positive, thermophilic spore-formers, which are found in a variety of environments from hot-springs, cool soils, to food manufacturing plants, including dairy manufacturing plants. Despite considerable interest in the use of Geobacillus spp. for biotechnological applications, the taxonomy of this genus is unclear, in part because of differences in DNA-DNA hybridization (DDH) similarity values between studies. In addition, it is also difficult to use phenotypic characteristics to define a bacterial species. For example, G. stearothermophilus was traditionally defined as a species that does not utilise lactose, but the ability of dairy strains of $G$. stearothermophilus to use lactose has now been well established.

Results: This study compared the genome sequences of 63 Geobacillus isolates and showed that based on two different genomic approaches (core genome comparisons and average nucleotide identity) the Geobacillus genus could be divided into sixteen taxa for those Geobacillus strains that have genome sequences available thus far. In addition, using Geobacillus stearothermophilus as an example, we show that inclusion of the accessory genome, as well as phenotypic characteristics, is not suitable for defining this species. For example, this is the first study to provide evidence of dairy adaptation in G. stearothermophilus - a phenotypic feature not typically considered standard in this species - by identifying the presence of a putative lac operon in four dairy strains.

Conclusions: The traditional polyphasic approach of combining both genotypic and phenotypic characteristics to define a bacterial species could not be used for G. stearothermophilus where many phenotypic characteristics vary within this taxon. Further evidence of this discordant use of phenotypic traits was provided by analysis of the accessory genome, where the dairy strains contained a putative lac operon. Based on the findings from this study, we recommend that novel bacterial species should be defined using a core genome approach.
\end{abstract}

Keywords: Geobacillus, Thermophile, Dairy, Comparative genomics

\section{Background}

The Geobacillus genus contains Gram-positive, rodshaped, spore-forming bacteria that have an optimum growth temperature of $55-65{ }^{\circ} \mathrm{C}$ [1]. Members of the Geobacillus genus were originally classified in Group 5 of the Bacillus genus [2]. In 2001, based on a combination of $16 \mathrm{~S}$ ribosomal RNA (rRNA) sequence analysis, fatty acid composition and DNA-DNA hybridization

\footnotetext{
*Correspondence: s.burgess1@massey.ac.nz; p.biggs@massey.ac.nz ${ }^{1}$ School of Food and Nutrition, Massey University, Palmerston North, New Zealand

${ }^{3}$ Statistics and Bioinformatics Group, Institute of Fundamental Sciences, Massey University, Palmerston North, New Zealand

Full list of author information is available at the end of the article
}

(DDH), some members of Group 5 were reclassified into the new genus Geobacillus, with the word Geobacillus meaning "soil or earth small rod" [1]. Recently it was proposed that the Geobacillus genus be separated into two genera based on a comparative genomics analysis, which we explore further here [3]. There is extensive interest in the Geobacillus genus for biotechnological purposes such as for bioremediation, the production of thermostable enzymes, and biofuels [4-7]. In addition, Geobacillus spp. are common spoilage organisms in food manufacturing plants and products [8-14]. Geobacillus spp. have been isolated from temperate as well as hot environments including hot springs, oilfields, deep sea sediments, sugar refineries, canned foods, dehydrated vegetables and dairy 
factories. The species G. stearothermophilus was first described in 1920 and was isolated from canned cream-style corn. G. stearothermophilus is a common contaminant of dairy products, particularly milk powder and has also been isolated from dried soups and vegetables. Until the 1980s G. stearothermophilus was regarded as the only known obligate thermophile of the Bacillus genus [15, 16].

According to the LPSN bacterio.net [17], as of April 2017, there were sixteen Geobacillus species (G. caldoxylosilyticus, G. galactosidasius, G. icigianus, G. jurassicus, G. kaustophilus, G. lituanicus, G. stearothermophilus, G. subterraneus, G. thermantarcticus, G. thermocatenulatus, G. thermodenitrificans, G. thermoglucosidasius, G. thermoleovorans, G. toebii, G. uzenensis and G. vulcani) described with validly published names [1, 18-27]. However, the classification of many of these species remains uncertain. To date over 60 Geobacillus genomes have been sequenced, mainly to identify genes that could be used in different biotechnological applications [3]. Of these, there are eleven species with genome sequences of the type strain (G. caldoxylosilyticus NBRC 10776, G. icigianus DSM 28325, G. jurassicus DSM 15726, G. kaustophilus NBRC 102445, G. stearothermophilus ATCC 12980, G. subterraneus DSM 13552, G. thermoantarcticus M1, G. thermodenitrificans DSM 465 G. thermoglucosidasisus NBRC 107763, G. thermoleovorans DSM 5366, and G. toebii DSM 14590) [3, 28, 29]. Recent studies have shown that it is possible for a comparative genomics approach to resolve the taxonomy of this important genus $[3,30]$. However, the question still remains as to the most appropriate genomics tool for the classification of new species.

Despite the advances of the post-genomics age, there is still no consensus as to what characterizes a bacterial species [31, 32]. However, in describing a new bacterial species, the two methods on which the most emphasis has been placed are 16S rRNA gene sequence analysis and DDH, alongside various phenotypic methods [33]. However, in some cases, including the Geobacillus genus, the sequence similarity of the 16S rRNA is $>97 \%$ between species despite being distinct when the overall genome DNA similarity is analyzed using DDH [34-38]. Therefore the identification of new Geobacillus species generally relies on other approaches, such as DDH.

In general, DDH is also fraught with challenges as a method for the differentiation of bacterial species because it is laborious and there is a lack of reproducibility, reciprocation, and calibration of the method with a reference strain of a known DDH value [39-41]. In the case of new Geobacillus species, DDH values between studies show large variations [21, 27], which has led to the reclassification of some species of Geobacillus. Dinsdale et al. [21] showed that some of the previously published species were in fact synonymous with current species and should no longer be considered valid. For example, the described species G. kaustophilus [1, 38, 42], G. lituanicus [23] and G. vulcani [43] were shown to be synonymous with $G$. thermoleovorans. In addition, the described species G. gargensis [27] was synonymous with G. thermocatenulatus. Most of the disagreement in assigning new species to the Geobacillus genus comes from the DDH values used to distinguish strains being very different between studies. More recently it was proposed that the strains of G. kaustophilus and G. thermoleovorans should both be designated to the G. thermoleovorans species [3].

Other housekeeping genes, such as recN, recA, rpoB,

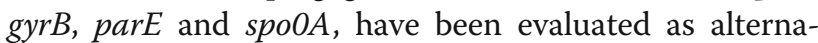
tives to the 16S rRNA gene for identifying Geobacillus species, all with limited success [37, 44-46]. Of the genes analyzed, recN appears to be the most reliable, with a higher taxonomic resolution compared with $16 \mathrm{~S}$ rDNA [46]. However, the taxonomic resolution between some species of Geobacillus is still poor (for example, between G. subterraneus and G. uzenensis). This is not surprising given that house-keeping genes are well conserved between closely related species, and relying on one or a few genes does not depict the real diversity of the entire genome.

In the era of next generation sequencing it is likely that DDH will become outdated. This is already apparent with the proposal to use comparative genomics approaches to demarcate new species with genomic DNA as the type material archived alongside live cultures $[47,48]$. There are a number of different ways in which whole genome sequence data can be used in taxonomy; for example, average nucleotide identity (ANI), tetranucleotide frequency, core genome analysis, pan genome analysis, and multilocus sequence typing (MLST) [49]. There appear to be two schools of thought on how a genomics based method should be incorporated into prokaryotic taxonomy. Firstly, there is a traditional polyphasic approach that incorporates both genomic as well as phenotypic characteristics [50]. In this case, the most likely substitute for DDH is ANI $[33,47]$. It has been shown that an ANI value of $<95-96 \%$ generally corresponds well with the thresholds of $<70 \%$ for DDH and $<97-98 \%$ for $16 \mathrm{~S}$ rRNA gene identity for defining new species $[40,51]$. Secondly, there is a reliance on a genomic approach only, simply using a core genome analysis or a combination of core genome and ANI $[52,53]$.

Until recently, none of the broader taxonomic studies on the Geobacillus genus have included G. stearothermophilus strains of dairy origin as part of their comparison. Traditionally both a genotypic and phenotypic analysis is carried out to identify a new species. However, the relationship between phenotype and genotype is not always straightforward. This is particularly well exemplified 
with dairy strains of G. stearothermophilus, which show unique physiological characteristics such as their metabolism (e.g. the ability to utilize lactose), and the fatty acid profile from the type strain G. stearothermophilus ATCC 12980 [54]. Differences in phenotypic traits may therefore result from niche adaptation, possibly mediated by differential gene expression, without major changes to the genome as a whole.

The aims of this study were two-fold: firstly, to establish whether the species boundaries of the G. stearothermophilus taxon could exclusively be determined by wholegenome sequence analyses, and secondly to determine whether the genomes of the dairy strains of G. stearothermophilus provide evidence of niche adaptation in ways that deviate from the standard phenotypic spectrum of the species. To pursue these goals, we compared the genome sequences of 63 Geobacillus strains, including twelve G. stearothermophilus strains, of which four were isolated from a dairy manufacturing environment.

\section{Results}

To gain an understanding of how the G. stearothermophilus strains isolated from dairy manufacture are related to other Geobacillus species, two different phylogenomic approaches were taken: ANI and a comparison of the core genomes. In addition, these methods were evaluated for their ability to replace the traditional methods of DDH, 16S rRNA sequence analysis and phenotypic characteristics to define a bacterial taxon, using G. stearothermophilus as an exemplar. The genomes of 63 Geobacillus strains (including ten type strains) were compared, of which eight strains were originally isolated from a dairy manufacturing environment or food product. Four of the eight strains were G. stearothermophilus, three of which were isolated from a New Zealand milk powder manufacturing and the fourth was isolated in the Netherlands from buttermilk powder [55, 56]. Within the Geobacillus genus the G. stearothermophilus type strain ATCC1290 had the smallest genome (2.63 Mb) compared with the dairy strain G. caldoxylosilyticus B4119 which has the largest genome size $(3.95 \mathrm{Mb})$ within the Geobacillus genus (Additional file 1: Table S1). The genome sizes of the G. stearothermophilus dairy strains ranged from 2.77 to $3.02 \mathrm{Mb}$.

\section{Phylogenetic relationships within the Geobacillus genus based on core genome comparisons}

A core genome analysis was used to determine phylogenetic relationships within the Geobacillus genus and to establish the species boundary of the G. stearothermophilus taxon. The core genome was defined using the program OrthoMCL, in which each orthologous group contained only one gene from each genome. In addition, to be included in the core genome, the length range (between the smallest and the largest) of the amino acid sequences within each cluster was not allowed to vary by more than $20 \%$. A phylogenetic network was then generated using the concatenated sequence of those orthologous genes (Fig. 1). Core genome comparisons separated the Geobacillus genus (Subset A, Table 1) into sixteen main groups and several sub-groups. Genomes of strains isolated from a dairy environment, indicated by asterisks, included strains of G. thermoglucosidasius, G. caldoxylosilyticus, G. kaustophilus and the focus of this study G. stearothermophilus.

To analyze the relationship of the G. stearothermophilus taxon more closely, comparison of the core genome was carried out on two smaller groups of Geobacillus taxa (Subset B and C, Table 1, Fig. 1b and c). There is a clear delineation between the G. stearothermophilus cluster and other closely related Geobacillus taxa (Groups 1-5, Fig. 1b). Within the G. stearothermophilus taxon three of the dairy strains (all from the same manufacturing plant) clustered together, showing no sequence diversity between strains A1 and P3 (Fig. 1c).

\section{Defining taxa in Geobacillus on the basis of ANI calculations}

As stated above, the most feasible substitute for DDH is ANI [33, 47]. To examine the use of ANI for demarcating species of the Geobacillus genus, ANIm frequencies were calculated for all of the sequenced genomes of the Geobacillus genus (Additional file 1: Table S2) and visualized using a heat-map (Fig. 2). Two ANI values were calculated for each pair of genomes with one being the subject and the other the query, and vice versa. The heat-map was non-symmetrical as a result of greater differences between the ANIm value and its reciprocal value for some pairs of genomes. When the difference between two ANIm values is greater than $0.5 \%$ around the $95 \%$ threshold it could potentially place ambiguity around the taxonomic position of a strain. However, this was not seen in this study, where the difference in two ANIm values between two members of the same taxon was always less than $0.5 \%$ (data not shown), so that there were clear demarcations between taxa (as designated by a red box in Fig. 2). The G. stearothermophilus strains had ANIm values $>95 \%$ grouping them within the same taxon.

\section{Phenotypic characteristics as taxonomic determinants}

To date, descriptions of novel bacterial species have included unique phenotypic characteristics. However, many descriptions are based on only a small population of strains, and in some cases, only one strain. When a larger population is examined, phenotypic characteristics can often vary between strains of the same taxon [32]. This was seen within the G. stearothermophilus taxon 

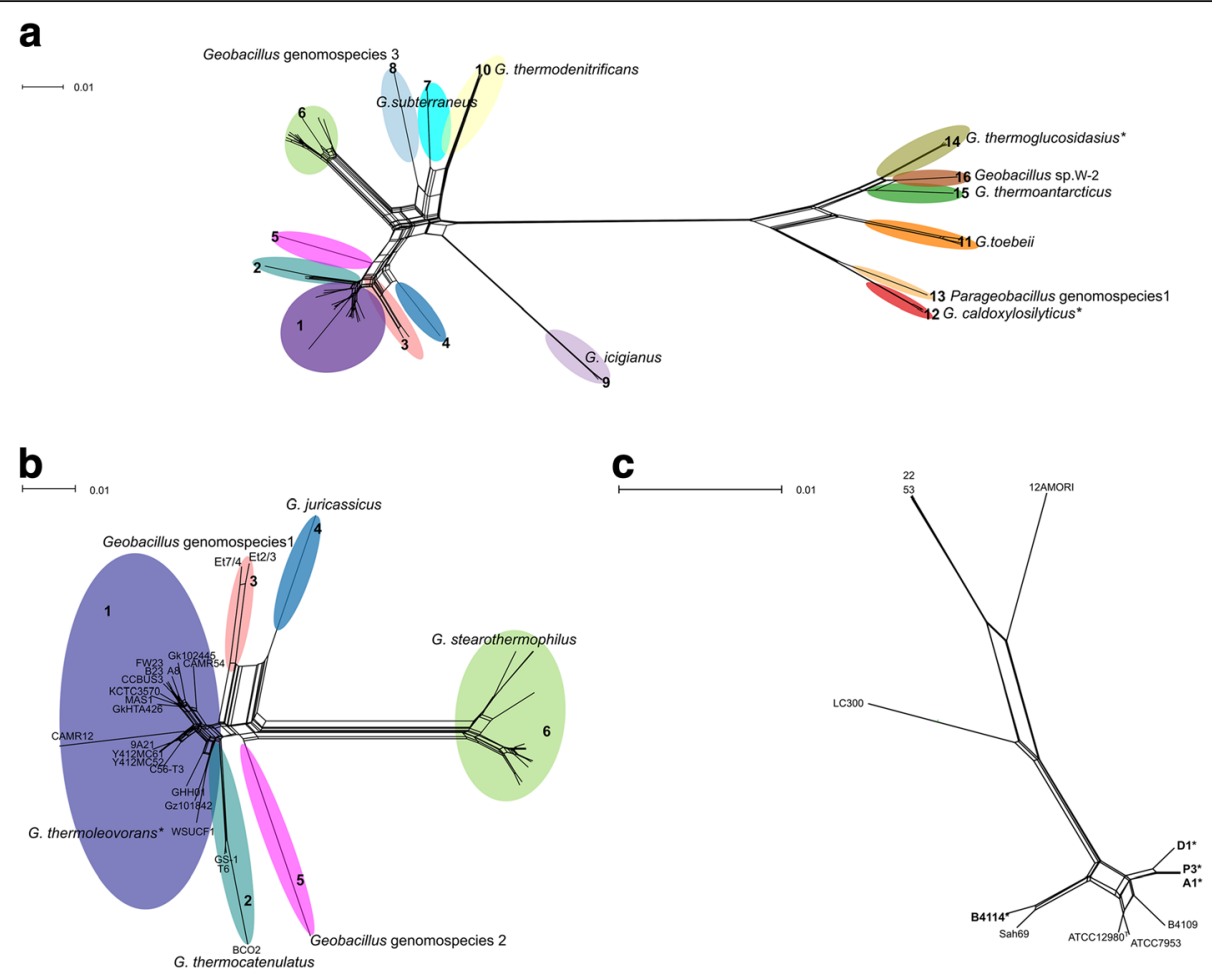

Fig. 1 Core genome sequence comparisons. The phylogenetic networks were generated using the Neighbor-Net algorithm in SplitsTree (v. 4.13.1). The orthologous groups were defined using the program OrthoMCL (v. 2.0.9) and the analyses were based on those genes that have orthologous gene members with a length range less than or equal to $20 \%$. Those groups marked with an asterisk contain a strain(s) that originate from a dairy environment. a. Includes all of the Geobacillus genomes where G. thermoleovorans group 1 refers to strains B23, CCB_US3_UF5, CAMR5420, FW23, MAS1, NBRC 102445, A8, Y412MC52, Y412MC61, 9A21, C56-T3, GHH01, WSUCF1 and HTA426, KCTC 3570, and G. zalihae NBRC 101842; Group 2 refers to "G. thermocatenocatulatus" strains GS-1, T6, and BC02; Group 3 refers to Geobacillus genomospecies 1 strains Et7/4 and Et2/3; Group 4 refers to G. juracassicus; Group 5 refers to Geobacillus genomospecies 2 strain PSS1; G. stearothermophilus Group 6 includes strains ATCC 12980, ATCC 7953, A1, P3, D1, B4114, 22, 53, Sah69, 12AMORI, LC300 and B4109; G. subterraneus Group 7 includes strains KCTC 3922 and K; Group 8 refers to Geobacillus genomospecies 3 strain JF8; G. icigianus Group 9 refers to strains PSS2 and G1w1T; G. toebii Group 10 includes strains NBRC 107807, WCH70 and B4110; G thermodenitrificans Group 11 includes strains DSM 465, NG80-2, PA3 and G11MC16; G. caldoxylosilyticus Group 12 includes strains CIC9, B4119 and NBRC 10776; Group 13 refers to Parageobacillus genomospecies 1 strain NUB3621; G. thermoglucosidasius Group 14 includes strains NBRC 10776, C56YS93, TNO-09 and Y4.1MC1; G. thermoantarcticus Group 15 includes strain M1; Group 16 includes strain W-2. b. Includes Groups 1-6. c. Includes G. stearothermophilus Group 6 only

(Table 2), where the use of phenotypic characteristics was not a reliable taxonomic determinant. Several phenotypic characteristics were different between the dairy strains and that described for the G. stearothermophilus species, as well as differences identified between the dairy strains themselves (Table 2).

\section{Unique accessory genes required for adaptation to a dairy environment}

Recently the genomes of four dairy strains of G. stearothermophilus have been sequenced $[54,55]$. The accessory genomes of these four strains were analyzed to determine whether the presence or absence of genes or

Table 1 Number of genes and amino acids used in the OrthoMCL clustering

\begin{tabular}{|c|c|c|c|c|c|c|c|c|}
\hline \multirow[t]{2}{*}{ Subset $^{a}$} & \multirow[t]{2}{*}{ Members of group } & \multicolumn{2}{|c|}{$\begin{array}{l}\text { Same length and } \\
\text { same sequence }\end{array}$} & \multicolumn{2}{|c|}{$\begin{array}{l}\text { Same length and } \\
\text { different sequence }\end{array}$} & \multicolumn{2}{|c|}{ Cluster length $^{\mathrm{b}}$} & \multirow[t]{2}{*}{$\begin{array}{l}\text { Total number } \\
\text { of core genes }\end{array}$} \\
\hline & & Genes & Amino acids & Genes & Amino acids & Genes & Amino acids & \\
\hline A & All Geobacillus & 1 & 116 & 58 & 7678 & $390^{c}$ & 81,812 & 391 \\
\hline B & Groups $1-6^{d}$ & 7 & 865 & 131 & 19,180 & $478^{c}$ & 99,197 & 485 \\
\hline C & G. stearothermophilus group & 138 & 19,490 & 992 & 277,724 & $1524^{c}$ & 446,984 & 1662 \\
\hline
\end{tabular}

\footnotetext{
aefer also to Fig. 1
}

${ }^{\mathrm{b}}$ To be in an orthologous cluster, genes had to have a length range of $20 \%$ across all cluster members, and only one member per strain

'This number of genes was used in the Neighbor-Net analysis

${ }^{\mathrm{d}}$ Refer to Fig. 1 for strains included in each group

eIncludes strains ATCC 12980, ATCC 7953, LC300, 12AMORI, 22, 53, Sah69, A1, P3, D1, B4109, B4114 


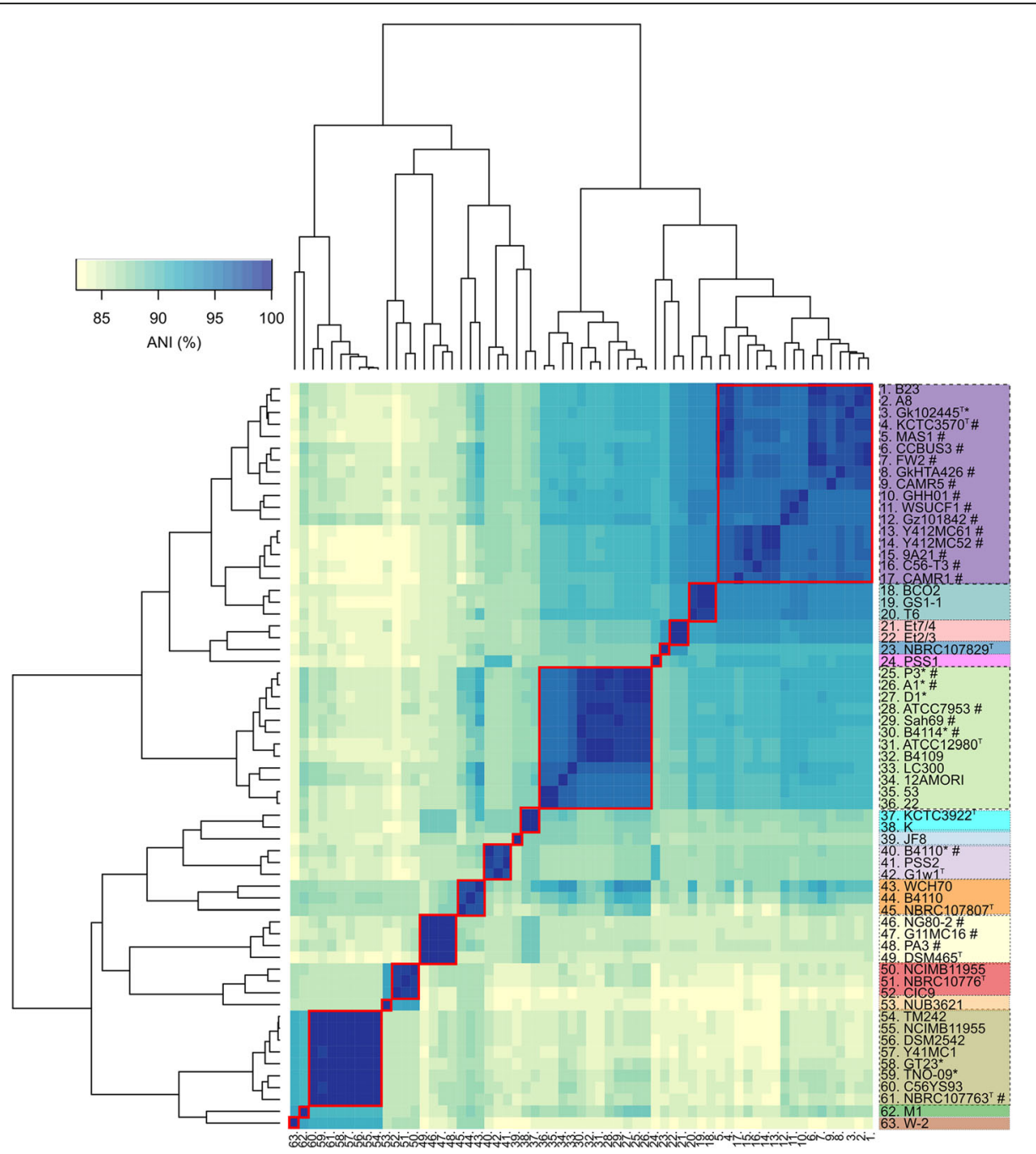

Fig. 2 Heat map comparison of the ANIm values. Those strains marked with an asterisk were isolated from a dairy environment and those strains marked with a hash were placed in a different order for the reciprocal pairwise comparison by the dendrogram option using the heatmap.2 function in R. Those ANI values greater than $95 \%$, grouping the strains within the same species, were enclosed by a red box

gene clusters could account for any of the phenotypic differences observed between the dairy strains and the type strain (ATCC 1294). A putative lac operon was identified in the dairy strains of G. stearothermophilus that was not found in any of the other Geobacillus genomes analysed, with the exception of G. stearothermophilus strain Sah69 that originates from soil. For all four dairy strains and strain Sah69, the putative lacA, lacB and lacC genes showed highest homology (95-99\% amino acid identity) with Bacillus smithii and the lacE, $l a c F$ and $b g l C$ genes showed highest homology (70-79\% amino acid identity) with Bacillus cereus. The gene organisation of these lac operons were compared with the lac operon of Staphylococcus aureus, and as seen in Fig. 3, they are missing the lacG gene, which encodes a galactosidase, required for splitting lactose into galactose and glucose. Instead of a galactosidase, they contained a gene encoding a glucosidase, annotated as $\mathrm{bglC}$. However, the two enzymes LacG and BglC are closely related, and in Lactococcus lactis, it has been shown that a glucosidase enzyme can act as a galactosidase under certain conditions $[57,58]$. The dairy strain B4114 contained an additional gene within this putative lac operon, which is homologous $(85 \%$ amino acid identity) to the $B$. smithii gatA gene, which is predicted to encode subunit IIA of a sugar phosphotransferase system [59]. The putative lac operon was also unique to the G. stearothermophilus taxon. The other dairy strains examined (G. kaustophilus NBRC 102445, G. thermoglucosidasisus strains TNO and GT23, and G. caldoxylosilyticus B4119) did not contain this putative lac operon (data not shown). 
Table 2 Phenotypic characteristics ${ }^{\mathrm{a}}$ of $\mathrm{G}$. stearothermophilus strains

\begin{tabular}{|c|c|c|c|c|c|c|c|}
\hline Characteristic & $\mathrm{A} 1^{\mathrm{b}, \mathrm{g}}$ & $\mathrm{D} 1^{\mathrm{b}, \mathrm{g}}$ & $P 3^{b, g}$ & Dairy $^{c}$ & ATCC $7953^{d}$ & ATCC $12980^{\mathrm{e}}$ & Species description $^{f}$ \\
\hline$\overline{\text { Motility }}$ & - & - & + & $\mathrm{v}$ & $n / d$ & $n / d$ & + \\
\hline \multicolumn{8}{|l|}{ Acid from: } \\
\hline Adonitol & - & - & - & - & - & $-{ }^{*} n / d$ & - \\
\hline Amidon $^{g}$ & - & + & - & v & $+^{*}$ & $v^{*}$ & $n / d$ \\
\hline Arabinose & w & - & w & $w /-$ & - & - & v \\
\hline Cellubiose $^{g}$ & + & + & + & + & v & $-^{*}$ & - \\
\hline Fructose & + & + & + & + & + & + & + \\
\hline Galactose $^{\mathrm{g}}$ & w & + & + & w/+ & - & $v$ & - \\
\hline Gentiobiose $^{h}$ & - & - & - & v & $-*$ & v & - \\
\hline Glucose & $n / d$ & $n / d$ & $n / d$ & + & + & + & + \\
\hline Glycerol & $n / d$ & $n / d$ & $n / d$ & - & $+^{*}$ & v & + \\
\hline Glycogen ${ }^{g, h}$ & - & - & - & v & $+^{*}$ & + & + \\
\hline Inositol & - & - & - & - & - & - & - \\
\hline Inuling & - & - & - & - & - & v & + \\
\hline Lactose $^{g}$ & + & + & + & + & - & $-^{*}$ & - \\
\hline Maltose & $n / d$ & $n / d$ & $n / d$ & + & + & + & + \\
\hline Mannitol & - & - & - & - & Var & - & Var \\
\hline Mannose $^{h}$ & + & + & + & v & $+^{*}$ & + & + \\
\hline Melezitose $^{\text {h }}$ & - & + & - & v & $+^{*}$ & + & + \\
\hline Melibiose & + & + & + & $v$ & $+^{*}$ & + & + \\
\hline MethylD-glucoside ${ }^{g, h}$ & - & - & - & v & $n / d$ & + & + \\
\hline Raffinose' h & $n / d$ & $n / d$ & $n / d$ & v & v & + & + \\
\hline Rhamnose & - & - & - & - & - & - & - \\
\hline Ribose & - & - & - & - & $-^{*}$ & - & - \\
\hline Salicin ${ }^{g, h}$ & + & + & + & v & $-*$ & v & - \\
\hline Sorbitol & - & - & - & - & - & - & - \\
\hline Sucrose & + & + & + & + & + & + & + \\
\hline Trehalose $^{\text {h }}$ & + & - & + & v & $+^{*}$ & + & + \\
\hline D-Turanose ${ }^{h}$ & - & - & - & v & $+^{*}$ & + & $v$ \\
\hline Xylose & - & - & - & - & - & $-^{*}$ & v \\
\hline \multicolumn{8}{|l|}{ Utilization of: } \\
\hline Citrate & - & - & - & - & - & $n / d$ & - \\
\hline Formate & & & & $n / d$ & & & - \\
\hline Lactate & & & & $n / d$ & & & - \\
\hline \multicolumn{8}{|l|}{ Hydrolysis of } \\
\hline Casein & - & - & - & - & v & $n / d$ & v \\
\hline Esculin & + & + & + & + & v & $n / d$ & v \\
\hline Gelatin $^{9}$ & - & - & - & - & + & $n / d$ & + \\
\hline Starch 9 & - & - & - & & + & $n / d$ & + \\
\hline
\end{tabular}


Table 2 Phenotypic characteristics ${ }^{\mathrm{a}}$ of G. stearothermophilus strains (Continued)

\begin{tabular}{|c|c|c|c|c|c|c|c|}
\hline Nitrate reduction & + & + & + & + & + & $\mathrm{n} / \mathrm{d}$ & $\vee$ \\
\hline Phenylalanine deamination & - & - & - & - & $\mathrm{n} / \mathrm{d}$ & $n / d$ & $n / d$ \\
\hline L-Pyroglutamic acid ${ }^{\text {h }}$ & - & + & - & $v$ & $\mathrm{n} / \mathrm{d}$ & $n / d$ & $n / d$ \\
\hline p-Nitrophenyl- $\beta$-D-glucoside ${ }^{g}$ & + & - & + & $\vee$ & $\mathrm{n} / \mathrm{d}$ & $\mathrm{n} / \mathrm{d}$ & $n / d$ \\
\hline
\end{tabular}

${ }^{a}$ Abbreviations are as follows: $v$, variable; $w$, weak reaction; $n / d$, not described

${ }^{\mathrm{b}}$ Data from this present study and Burgess et al. [54]

'Data from Flint et al. [10] and Burgess et al. [54]

${ }^{\mathrm{d}}$ Data from this present study (marked as *), Baldock [95], Humbert et al. [96] and Jung et al. [97]

eData from this present study (marked as *), Walker and Wolf [98], Logan and Berkeley [99] and Flint et al. [10]

${ }^{f}$ As described by Logan et al. [70]

9Phenotypic characteristic that is variable between the dairy strains

hPhenotypic characteristic that is different between the dairy strains and that described for the G. stearothermophilus species

\section{Discussion}

Traditionally the taxonomic classification of bacterial species has relied on $16 \mathrm{~S}$ rDNA sequence analysis, DDH similarity values and phenotypic characteristics. It is challenging to classify strains to a species within the Geobacillus genus based solely on the $16 \mathrm{~S}$ rRNA gene due to its high sequence similarity across the genus. It is likely that this has resulted in the mis-identification of many Geobacillus strains as demonstrated here and elsewhere [3, 20, 21]. Several strains analyzed in this study were previously mis-identified as G. stearothermophilus, for example, strain BGSC 9A21. This strain was isolated prior to the 1980s when it was believed that G. stearothermophilus was the only obligate thermophile of the Bacillus genus [60]. Although, the 16S rRNA gene sequence of this strain is approximately $98 \%$ to the type strain of G. stearothermophilus ATCC 12980, it is also 98-99\% similar to other type strains of the Geobacillus genus and based on other genomic evidence is actually more closely related to $G$. thermoleovorans as demonstrated in this study. Generally isolates with $<97 \%$ identity for the $16 \mathrm{~S}$ rRNA gene are regarded as separate species [30,33]. More recently, it was proposed that this threshold for demarcating species should be increased to $98.65 \%$ [48]. In reality, setting a threshold based on 16S rRNA gene similarity, let alone such a specific number, does not work.

The taxonomic classification of Geobacillus species is also uncertain, due to differences in DNA-DNA hybridization (DDH) similarity values between studies. Novel bacterial taxon descriptions also rely on phenotypic descriptions, but phenotypic characteristics may vary within a taxon. To circumvent these issues, a comparative genomics approach was taken to determine whether genome sequence data could replace the traditional methods of 16S rRNA sequence analysis, DDH, and phenotypic characteristics for defining bacterial taxa, using G. stearothermophilus as an exemplar.

The Geobacillus genus could be divided into sixteen taxa, based on both a core genome comparison and ANI, for those Geobacillus strains that had genome sequences available at the time of analysis. Of these, twelve appear to have validly published names (G. caldoxylosilyticus, G. icigianus, G. juricassicus, G. stearothermophilus, G. subterraneus, G. thermoantarcticus, G. thermocatenulatus, G. thermodenitrificans, G. thermoglucosidasius, G. thermoleovorans, G. toebeii and G. vulcani). Previous studies disagree on whether G. thermocatenulatus can be regarded as a separate species [21, 61, 62] and

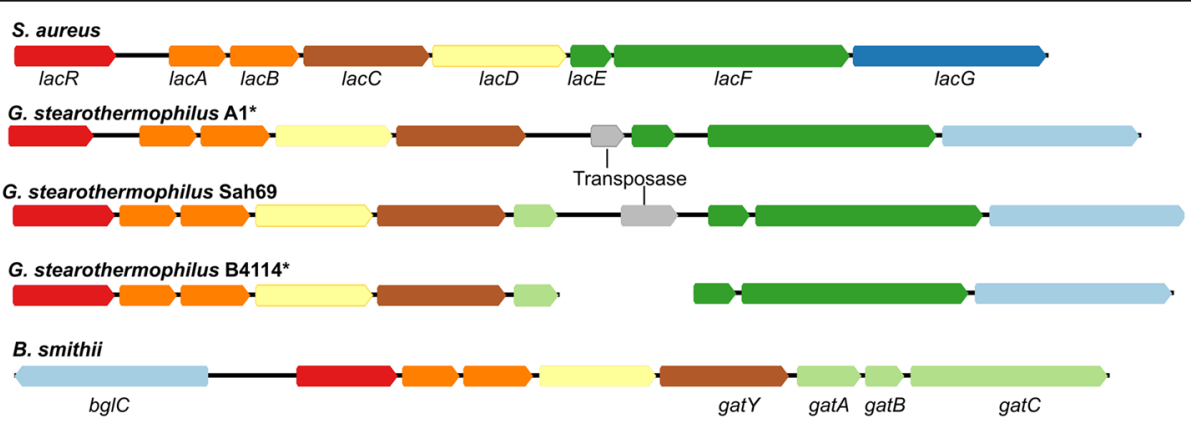

Fig. 3 Comparison of the organisation of the lac genes. Annotations are based on the assigned KEGG KO for each gene. Colours represent those genes belonging that to the same KO group and/or KEGG enzyme entry. The lac operon in S. aureus and the putative lac operons in strains A1, Sah69, B4114 as well as B. smithii (which showed the highest similarity to the putative lacA, lacB and lacC genes from strain A1). Those strains marked with an asterisk were isolated from a dairy environment. The gene organisation of the putative lac operon in strains P3 and D1 was syntenic with that of $\mathrm{A} 1$. The gat $A B C$ operon encodes a galactitol transport system and gat $Y$ a component of the of the GatYZ tagatose aldolase as described byVan der Heiden et al. [82]. GatY and LacD both belong to the same enzyme group (EC 4.1.2.40) 
analysis of further G. thermocatenulatus strains as well as the type strain will be required to determine its taxonomic position. The taxonomic position of G. zalihae is also unclear. It bordered on the ANIm demarcation threshold from genomes in the G. thermoleovorans group (95.8-96.1\%), although it formed a sub-group within Group 1, which may indicate that it is a subspecies of $G$. thermoleovorans rather than a separate species. In contrast, other studies describe G. zalihae as a genomospecies [3]. This highlights a need for clearer guidelines on how whole genome sequence analyses are interpreted to identify novel species.

In this present study, a phylogenetic network was generated for making core genome comparisons. An advantage of using a phylogenetic network, as opposed to a branching phylogenetic tree, is that it can show any ambiguous signal as to the taxonomic relationship between strains [63]. Ambiguous signal can arise from events such as gene duplication, gene transfer, different rates of mutation and recombination [64]. A comparative genomics approach used to re-examine the taxonomy of the Geobacillus genus demonstrated that the Geobacillus genus could be divided into two clades, and proposed that clade II be considered as the new genus Parageobacillus. This is also consistent with our results where a phylogenetic network generated using 332 core genes, showed a clear delineation between Groups 1-10 and Groups 11-16. However, distinct clades within a bacterial genus are not unusual $[52,65,66]$; separation of the Geobacillus genus into two genera should also be made on additional criteria, such as a discrete set of phenotypic characteristics separating the two clades. There were differences between our study and the recent analysis of Aliyu et al. [3], which compared a larger number of core genes $(n=1048)$. This is unexpected, given they examined a larger number of genomes, so the number of core genes might be expected to be lower compared with this present study. The most likely explanation is that the criteria used for defining the core genome in this present study were more stringent than that used in Aliyu et al. [3]. A core genome comparison of Geobacillus spp. was carried out by Studholme [30]; however, that analysis only included genome sequences in the G. thermoleovorans, G. kaustophilus and G. thermocatenulatus group. The groupings found were similar to those identified here using the OrthoMCL clustering, providing evidence that core genome comparisons are broadly comparable between research groups (although we note that Studholme [30] did not describe their method for determining the core genome).

The main focus of our study was on G. stearothermophilus. Compared with Groups 1-5 (Fig. 1.), G. stearothermophilus formed a discrete group, resulting in a clear delineation between G. stearothermophilus and the other Geobacillus taxa based on both core genome sequence analysis and ANI. Core genome sequence comparisons provided genomic evidence that the dairy strains of G. stearothermophilus fell within the same clade as other members of the G. stearothermophilus taxon. Within G. stearothermophilus, distinct groups were defined by both the core genome and ANI analyses, perhaps indicative of subspecies.

There is no one school of thought on how genomics based methodologies should be incorporated into prokaryotic taxonomy. One approach is to find a substitution for DDH, such as ANI. The use of ANI for defining new species is not without its problems [64]. Two key issues are that the genome sequences of many type strains are not available, and there are many strains that have been incorrectly identified to a given species. In the analysis of Richter and Rossello-Mora [64], it was found that for those genomes with validly published names, only $45 \%$ actually belonged to the same species as the type strain (as defined by other means such as DDH). As of 31 July 2013, there were 10,546 validly published bacterial species names, but only $14.9 \%$ of these had genome sequences available for the type strain [47]. This issue has arisen within the Geobacillus genus when in defining the new species G. icigianus, Bryanskaya et al. [19] carried out an ANI analysis, which included the genome sequences of only two type strains. In this present study, it was also shown that some genomes with validly published names did not belong to the same species as the type strain. For example, based on a recN sequence analysis G. vulcani PSS1 did not belong to the same clade as the type strain G. vulcani DSM 3174. Although G. vulcani is a validly published name, it has previously been shown to be synonymous with $G$. thermoleovorans [21] and evidence is provided here that G. vulcani PSS1 is a novel species, as also supported by Aliyu et al. [3].

Another issue faced when using ANI is that it takes into account the entire genome, including accessory genes. Accessory genes are generally carried by mobile elements and acquired via horizontal gene transfer as a means of adapting to a specific environment [67]. For this reason, we believe ANI is not good measure of phylogeny. Importantly, as previously expressed by others, the use of ANI in replacing DDH appears to be a case of manipulating a new method to fit an old method [49, 68], rather than taking advantage of the much greater resolution of other aspects of the new dataset.

Traditionally, a polyphasic approach, combining both genotypic and phenotypic characteristics, is used for defining new species. In incorporating a genomics approach into prokaryotic taxonomy, it has been suggested that a polyphasic approach should still be used [50]. This could not be used for G. stearothermophilus because of the range of phenotypic variation observed between strains. Other phenotypic characteristics such as the 
fatty acid content have also been shown to differ between G. stearothermophilus strains [54]. Importantly, discernible phenotypic characteristics are dependent on certain genes being expressed; for example, changes in the growth conditions can change the manifestation of certain phenotypic traits. Unless strict standards are in place, it can be difficult to reproduce certain phenotypic characteristics between laboratories, such as bacterial cell components (for example, fatty acids) [50].

A description of G. stearothermophilus has not been republished since 1986 by Claus and Berkeley [69]; therefore, Logan et al. [70] advise that this description is likely to have encompassed a variety of thermophilic bacilli strains that would now be regarded as separate taxa. In addition, it did not take into account phenotypic differences that could occur between strains as a result of adaptation of to specific environmental niches (e.g. lactose utilization).

Further evidence of this discordant use of phenotypic traits was provided by analysis of the accessory genome, where the dairy strains contained a putative lac operon not found in the other genomes of G. stearothermophilus. The presence and absence of other gene clusters required for the utilization of different carbohydrates is not unusual in the Geobacillus genus. Zeigler [71] analysed ten Geobacillus genomes and found there was variation in the number of gene clusters predicted to be involved in plant polysaccharide degradation both within and between different taxa. This supports the notions derived in this current study that inclusion of the accessory genome is not a good measure of phylogeny because of their environmental specificity and therefore should not be used for describing new species.

It has been suggested that where there are important phenotypic differences between strains of the same species (as defined by the core genome), they should be described as "biovars" of a species, instead of using phenotypic differences as a measure of taxonomy [53]. In the same study it was found that within a population of Rhizobium leguminosarum, the accessory genome and the ability to utilize different carbon sources differed. The authors also use the Bacillus cereus group, as an example, suggesting that Bacillus anthracis and Bacillus thuringenisis be named as Bacillus cereus biovar anthracis and biovar thuringenisis respectively. This group of bacteria show a high degree of similarity based on their chromosomal DNA, raising the question as to whether they are separate species, as they can only be differentiated by their virulence characteristics [72]. Using the biovar concept, the dairy strains of G. stearothermophilus could be named G. stearothermophilus biovar lactis.

\section{Conclusions}

Two comparative genomics approaches were evaluated for their ability to define a bacterial species, in this case
G. stearothermophilus. Both genomic approaches (core genome comparisons and ANI) grouped the twelve strains of G. stearothermophilus together, with the core genome comparison demonstrating variation between eleven of the strains, particularly between the dairy and non-dairy strains. Comparison of the genomes was able to resolve differences between species of the Geobacillus genus that cannot be determined using the traditional approach of $16 \mathrm{~S}$ rRNA gene sequence analysis. However, although ANI was able to be used for demarcating taxa, it should not be used for determining phylogenetic relationships as it takes into account the accessory genome. When strains belonging to the same species are isolated from different environments, they may contain a different set of accessory genes as a way of adapting to a specific environment. This was seen in this present study where the dairy strains contained a unique set of genes that are probably required for lactose metabolism. A polyphasic approach for defining a bacterial species by combining genomic data with a broad range of phenotypic data would therefore not work for the G. stearothermophilus taxon due to the range of phenotypic variation observed between strains. Based on the findings from this study, we recommend that novel bacterial species should be defined using a core genome approach. However, for any genomic approach to become routine, all of the type strains would need to be sequenced first.

\section{Methods}

\section{Genome sequences}

The genome sequences of four dairy strains of G. stearothermophilus: three strains (A1, P3 and D1) isolated from a New Zealand milk powder manufacturing plant and one strain (B4114) isolated from buttermilk powder, $[55,56]$ were compared with the genome sequences of 59 other strains of Geobacillus (Additional file 1: Table S1) $[4-7,28,29,73-88]$. All of the genomes were parsed and re-annotated using Prokka v. 1.10 with default parameters [89].

\section{Average nucleotide identity (ANI)}

The ANI between two genomes has been proposed as an in-silico method to replace DDH [64]. This study used the default parameters in the JSpecies software package v. 1.2.1 to calculate the ANI using the program MUMmer (ANIm) between each pair of Geobacillus genomes. The ANIm values were used to compare the relationships between the Geobacillus genomes by generating a heat-map. The heat-map was generated using the heatmap. 2 function included in the gplots library of the statistics software package R v. 3.2.0, visualized in Rstudio v. 0.98.1103. 


\section{Core genome comparisons}

The program OrthoMCL v. 2.0.9 [90] was used to determine the core genome. Comparison of the core genome was based on predicted amino acid sequences from 'perfect sets' of orthologous gene clusters (i.e., for a given gene, there were no paralogues identified within a genome), as previously described [91]. The length range of the amino acid sequences within a cluster, used in this analysis, did not vary by more than $20 \%$ of the length of the longest gene. This value allows some variation, without being too flexible, in the length of the protein amongst all cluster members. Variation in predicted protein length may occur, for example, from the actual gene starting at a different start codon from that of the predicted annotation. The core genes were aligned individually using MUSCLE v. 3.8.31 [92] and concatenated. The Neighbor-Net algorithm [93] in SplitsTree v. 4.13.1 was used to generate a Neighbor-Net with the aligned sequences.

\section{Phenotypic characteristics}

Biochemical assays were carried out as described in Burgess et al. [54]. Motility was determined using the hanging drop method, as described by Harrigan [94], using cultures of G. stearothermophilus strains (A1, P3 and D1) grown in tryptic soya broth for $8 \mathrm{~h}$ at $55^{\circ} \mathrm{C}$.

\section{Additional file}

Additional file 1: Table S1. Lists the bacterial genomes used in this study. Table S2. This spreadsheet contains the ANIm values between each pair of genomes. (XLSX $48 \mathrm{~kb})$

\section{Acknowledgements}

We thank Roberto Kolter (Harvard Medical School, Boston, MA, USA) and Hera Vlamakis (Broad Institute, Cambridge, MA, USA) for their valued discussion on aspects of this project, and Haoran Wang (Massey University, Palmerston North, New Zealand) for her help with some of the laboratory work.

\section{Funding}

This study received no specific grant from any funding agency.

\section{Availability of data and materials}

The datasets supporting the conclusions of this article are included within the article and its additional files.

\section{Author's contributions}

SB designed the study, performed the analyses and drafted the manuscript. DL and SF provided project oversight, intellectual input and data interpretation. MC helped with analysis of the data and reviewed the manuscript; PB helped with the study design, prepared in-house Perl scripts, helped with the analyses and reviewed the manuscript. All authors read and approved the final manuscript.

\section{Competing interests}

The authors declare that they have no competing interests.

\section{Consent for publication}

Not applicable

Ethics approval and consent to participate Not applicable

\section{Publisher's Note}

Springer Nature remains neutral with regard to jurisdictional claims in published maps and institutional affiliations.

\section{Author details}

${ }^{1}$ School of Food and Nutrition, Massey University, Palmerston North, New Zealand. ${ }^{2}$ Fonterra Research Institute, Palmerston North, New Zealand. ${ }^{3}$ Statistics and Bioinformatics Group, Institute of Fundamental Sciences, Massey University, Palmerston North, New Zealand. ${ }^{4}$ Infectious Disease Research Centre, Institute of Veterinary, Animal and Biomedical Sciences, Massey University, Palmerston North, New Zealand.

Received: 22 June 2016 Accepted: 13 June 2017

Published online: 26 June 2017

References

1. Nazina TN, Tourova TP, Poltaraus AB. Taxonomic study of aerobic thermophilic bacilli: descriptions of Geobacillus subterraneus gen. nov., sp. nov. and Geobacillus uzenensis sp. nov. from petroleum reservoirs and transfer of Bacillus stearothermophilus, Bacillus thermocatenulatus, Bacillus thermoleovorans, Bacillus kaustophilus, Bacillus thermoglucosidasius and Bacillus thermodenitrificans to Geobacillus as the new combinations Geobacillus stearothermophilus, Geobacillus thermocatenulatus, Geobacillus thermoleovorans, Geobacillus kaustophilus, Geobacillus thermoglucosidasius and Geobacillus thermodenitrificans. Int J Syst Evol Microbiol. 2001;51:433-446.

2. Ash C, Farrow J, Wallbanks S, Collins M. Phylogenetic heterogeneity of the genus Bacillus revealed by comparative analysis of small subunit ribosomal RNA sequences. Lett Appl Microbiol. 1991;13:202-6.

3. Aliyu H, Lebre P, Blom J, Cowan D, De Maayer P. Phylogenomic reassessment of the thermophilic genus Geobacillus. Syst Appl Microbiol. 2016;39:527-33.

4. Bhalla A, Kainth AS, Sani RK. Draft genome sequence of lignocellulosedegrading thermophilic bacterium Geobacillus sp. strain WSUCF1. Genome Announc. 2013; doi:10.1128/genomeA.00595-13.

5. Boonmark C, Takahasi Y, Morikawa M. Draft genome sequence of Geobacillus thermoleovorans strain B23. Genome Announc. 2013; doi:10. 1128/genomeA.00944-13.

6. Feng L, Wang W, Cheng J, Ren Y, Zhao G, et al. Genome and proteome of long-chain alkane degrading Geobacillus thermodenitrificans NG80-2 isolated from a deep-subsurface oil reservoir. Proc Natl Acad Sci U S A. 2007;104:5602-7.

7. Wiegand S, Rabausch U, Chow J, Daniel R, Streit WR, Liesegang H. Complete genome sequence of Geobacillus sp. strain GHH01, a thermophilic lipase-secreting bacterium. Genome Announc. 2013; doi:10. 1128/genomeA.00092-13.

8. Donk PJ. A highly resistant thermophilic organism. J Bacteriol. 1920;5:373-4

9. Zhao Y, Caspers MPM, Metselaar Kl, de Boer P, Roeselers G, Moezelaar R, et al. Abiotic and microbiotic factors controlling biofilm formation by thermophilic sporeformers. Appl Environ Microbiol. 2013;79:5652-60.

10. Flint SH, Ward LH, Walker KMR. Functional grouping of thermophilic Bacillus strains using amplification profiles of the 16S-23S internal spacer region. Syst Appl Microbiol. 2001;24:539-48.

11. Scott SA, Brooks JD, Rakonjac J, Walker KMR, Flint SH. The formation of thermophilic spores during the manufacture of whole milk powder. Int J Dairy Technol. 2007;60:109-17.

12. Tai SK, Lin HPP, Kuo J, Liu JK. Isolation and characterization of a cellulolytic Geobacillus thermoleovorans T4 strain from sugar refinery wastewater. Extremophiles. 2004;8:345-9.

13. Luecking G, Stoeckel M, Atamer Z, Hinrichs J, Ehling-Schulz M. Characterization of aerobic spore-forming bacteria associated with industrial dairy processing environments and product spoilage. Int J Food Microbiol. 2013;166:270-9.

14. Postollec F, Mathot A-G, Bernard M, Divanac'h M-L, Pavan S, Sohier D. Tracking spore-forming bacteria in food: from natural biodiversity to selection by processes. Int J Food Microbiol. 2012;158:1-8.

15. Suzuki Y, Kishigami T, Inoue K, Mizoguchi Y, Eto N, Takagi M, et al. Bacillus thermoglucosidasius sp.nov, a new species of obligately thermophilic bacilli. Syst Appl Microbiol. 1983;4:487-95.

16. Zarilla KA, Perry JJ. Bacillus thermoleovorans, sp. nov. a species of obligately thermophilic hydrocarbon utilizing endospore-forming bacteria. Syst Appl Microbiol. 1987;9:258-64. 
17. LPSN:LPSN List of prokaryotic names with standing in nomenclature. http:// www.bacterio.net/geobacillus.html. Accessed 22 April 2017.

18. Ahmad S, Scopes RK, Rees GN, Patel BKC. Saccharococcus caldoxylosilyticus sp nov., an obligately thermophilic, xylose-utilizing, endospore-forming bacterium. Int J Syst Evol Microbiol. 2000;50:517-23.

19. Bryanskaya AV, Rozanov AS, Slynko NM, Shekhovtsov SV, Peltek SE, Geobacillus icigianus sp nov., a thermophilic bacterium isolated from a hot spring. Int J Syst Evol Microbiol. 2015;65:864-9.

20. Coorevits A, Dinsdale AE, Halket G, Lebbe L, De Vos P, Van Landschoot A, et al. Taxonomic revision of the genus Geobacillus: emendation of Geobacillus, G. stearothermophilus, G. jurassicus, G. toebii, G. thermodenitrificans and G. thermoglucosidans (nom. corrig., formerly 'thermog/ucosidasius'); transfer of Bacillus thermantarcticus to the genus as $G$. thermantarcticus comb. nov:; proposal of Caldibacillus debilis gen. nov., comb. nov.; transfer of G. tepidamans to Anoxybacillus as A. tepidamans comb. nov.; and proposal of Anoxybacillus caldiproteolyticus sp nov. Int J Syst Evol Microbiol. 2012;62:1470-85.

21. Dinsdale AE, Halket G, Coorevits A, Van Landschoot A, Busse H-J, De Vos P, et al. Emended descriptions of Geobacillus thermoleovorans and Geobacillus thermocatenulatus. Int J Syst Evol Microbiol. 2011;61:1802-10.

22. Fortina MG, Mora D, Schumann P, Parini C, Manachini PL, Stackebrandt E. Reclassification of Saccharococcus caldoxylosilyticus as Geobacillus caldoxylosilyticus (Ahmad et al. 2000) comb. nov. Int J Syst Evol Microbiol. 2001;51:2063-71.

23. Kuisiene N, Raugalas J, Chitavichius D. Geobacillus lituanicus sp nov. Int J Syst Evol Microbiol. 2004;54:1991-5.

24. Nazina TN, Sokolova DS, Grigoryan AA, Shestakova NM, Mikhailova EM, Poltaraus AB, et al. Geobacillus jurassicus sp. nov., a new thermophilic bacterium isolated from a high-temperature petroleum reservoir, and the validation of the Geobacillus species. Syst Appl Microbiol. 2005;28:43-53.

25. Poli A, Laezza G, Gul-Guven R, Orlando P, Nicolaus B. Geobacillus galactosidasius sp nov., a new thermophilic galactosidase-producing bacterium isolated from compost. Syst Appl Microbiol. 2011;34:419-23.

26. Sung MH, Kim H, Bae JW, Rhee SK, Jeon CO, Kim K, et al. Geobacillus toebii sp nov., a novel thermophilic bacterium isolated from hay compost. Int J Syst Evol Microbiol. 2002;52:2251-5.

27. Nazina TN, Lebedeva EV, Poltaraus AB, Tourova TP, Grigoryan AA, Sokolova DS, et al. Geobacillus gargensis sp nov., a novel thermophile from a hot spring, and the reclassification of Bacillus vulcani as Geobacillus vulcani comb. nov. Int J Syst Evol Microbiol. 2004;54:2019-24.

28. Bryanskaya AV, Rozonov AS, Logacheva MD, Kotenko AV, Peltek SE. Draft genome sequence of Geobacillus icigianus strain $\mathrm{G} 1 \mathrm{~W} 1^{\top}$ isolated from hot springs in the valley of geysers, Kamchatka (Russian Federation). Genome Announc. 2014; doi:10.1128/genomeA.01098-14.

29. Yao N, Ren Y, Wang W. Genome sequence of a thermophilic bacillus, Geobacillus thermodenitrificans DSM465. Genome Announc. 2013; doi:10. 1128/genomeA.01046-13.

30. Studholme DJ. Some (bacilli) like it hot: genomics of Geobacillus species. Microb Biotech. 2015;8:40-8.

31. Rossello-Mora R, Amann R. Past and future species definitions for bacteria and archaea. Syst Appl Microbiol. 2015;38:209-16.

32. Thompson CC, Amaral GR, Campeao M, Edwards RA, Polz MF, Dutilh BE, et al. Microbial taxonomy in the post-genomic era: rebuilding from scratch? Arch Microbiol. 2015:197:359-70.

33. Tindall BJ, Rossello-Mora R, Busse HJ, Ludwig W, Kaempfer P. Notes on the characterization of prokaryote strains for taxonomic purposes. Int J Syst Evol Microbiol. 2010;60:249-66.

34. Coorevits A, De Jonghe V, Vandroemme J, Reekemans R, Heyrman J, Messens W, et al. Comparative analysis of the diversity of aerobic sporeforming bacteria in raw milk from organic and conventional dairy farms. Syst Appl Microbiol. 2008;31:126-40.

35. Rainey FA, Fritze D, Stackebrandt E. The phylogenetic diversity of thermophilic members of the genus Bacillus as revealed by $16 \mathrm{~S}$ rDNA analysis. FEMS Microbiol Lett. 1994;115:205-11.

36. Stackebrandt E, Goebel BM. A place for DNA-DNA reassociation and 165 ribosomal-RNA sequence-analysis in the present species definition in bacteriology. Int J Syst Bacteriol. 1994:44:846-9.

37. Weng FY, Chiou CS, Lin PHP, Yang SS. Application of recA and rpoB sequence analysis on phylogeny and molecular identification of Geobacillus species. J Appl Microbiol. 2009;107:452-64.
38. White D, Sharp RJ, Priest FG. A polyphasic taxonomic study of thermophilic bacilli from a wide geographical area. Antonie Van Leeuwenhoek. 1994;64: $357-86$.

39. Emerson D, Agulto L, Liu H, Liu L. Identifying and characterizing bacteria in an era of genomics and proteomics. Bioscience. 2008:58:925-36.

40. Goris J, Konstantinidis KT, Klappenbach JA, Coenye T, Vandamme P, Tiedje JM. DNA-DNA hybridization values and their relationship to whole-genome sequence similarities. Int J Syst Evol Microbiol. 2007;57:81-91.

41. Stackebrandt $E$. The richness of prokaryotic diversity: there must be a species somewhere. Food Technol Biotechnol. 2003;41:17-22.

42. Priest FG, Goodfellow M, Todd C. A numerical classification of the genus Bacillus. J Gen Microbiol. 1988;134:1847-82.

43. Caccamo D, Gugliandolo C, Stackebrandt E, Maugeri TL. Bacillus vulcani sp nov., a novel thermophilic species isolated from a shallow marine hydrothermal vent. Int J Syst Evol Microbiol. 2000;50:2009-12.

44. Kuisiene N, Raugalas J, Chitavichius D. Phylogenetic, inter, and intraspecific sequence analysis of spoOA gene of the genus Geobacillus. Curr Microbiol. 2009;58:547-53.

45. Tourova TP, Korshunova AV, Mikhailova EM, Sokolova DS, Poltaraus AB, Nazina TN. Application of gyrB and parE sequence similarity analyses for differentiation of species within the genus Geobacillus. Microbiology. 2010;79:356-69.

46. Zeigler DR. Application of a recN sequence similarity analysis to the identification of species within the bacterial genus Geobacillus. Int I Syst Evol Microbiol. 2005;55:1171-9.

47. Chun J, Rainey FA. Integrating genomics into the taxonomy and systematics of the bacteria and archaea. Int J Syst Evol Microbiol. 2014;64:316-24.

48. Whitman WB. Genome sequences as the type material for taxonomic descriptions of prokaryotes. Syst Appl Microbiol. 2015;38:217-22.

49. Thompson CC, Chimetto L, Edwards RA, Swings J, Stackebrandt E, Thompson FL. Microbial genomic taxonomy. BMC Genomics. 2013; doi:10 1186/1471-2164-14-913.

50. Kampfer P, Glaeser SP. Prokaryotic taxonomy in the sequencing era - the polyphasic approach revisited. Environ Microbiol. 2012;14:291-317.

51. Kim M, Oh H-S, Park S-C, Chun J. Towards a taxonomic coherence between average nucleotide identity and 16S rRNA gene sequence similarity for species demarcation of prokaryotes. Int I Syst Evol Microbiol. 2014;64:346-51.

52. Chan JZM, Halachev MR, Loman NJ, Constantinidou C, Pallen MJ. Defining bacterial species in the genomic era: insights from the genus Acinetobacter. BMC Microbiol. 2012; doi:10.1186/1471-2180-12-302.

53. Kumar N, Lad G, Giuntini E, Kaye ME, Udomwong P, Shamsani NJ, Young JPW, Bailly X. Bacterial genospecies that are not ecologically coherent: population genomics of Rhizobium leguminosarum. Open Biol. 2015;doi:10. 1098/rsob.140133

54. Burgess SA, Flint SH, Lindsay D. Characterization of thermophilic bacilli from a milk powder processing plant. J Appl Microbiol. 2014;11:350-9.

55. Burgess SA, Cox MP, Flint SH, Lindsay D, Biggs PJ. Draft genome sequences of three strains of Geobacillus stearothermophilus isolated from a milk powder manufacturing plant. Genome Announc. 2015; doi:10.1128/ genomeA.00939-15.

56. Berendsen EM, Wells-Bennik MHJ, Krawczyk AO, de Jong A, van Heel A, Holsappel S, Eijlander RT, Kuipers OP. Draft Genome sequences of seven thermophilic sporeforming bacteria isolated from foods that produce highly heat-resistant spores, comprising Geobacillus spp., Caldibacillus debilis, and Anoxybacillus flavithermus. Genome Announc. 2016. doi: 10.1128/genomeA.00105-16.

57. Aleksandrzak-Piekarczyk T, Kok J, Renault P, Bardowski J. Alternative lactose catabolic pathway in Lactococcus lactis IL1403. Appl Environ Microbiol. 2005; 71:6060-9.

58. Hall BG. Predicting evolutionary potential. I. Predicting the evolution of a lactose-PTS system in Escherichia coli. Mol Biol Evol. 2001;18:1389-400.

59. Van der Heiden E, Delmarcelle M, Lebrun S, Freichels R, Brans A, Vastenavond CM, et al. A pathway closely related to the D-tagatose pathway of gram-negative Enterobacteria identified in the gram-positive bacterium Bacillus licheniformis. Appl Environ Microbiol. 2013;79:3511-5.

60. Stenesh J, Roe BA. DNA polymerase from mesophilic and thermophilic bacteria: I. Purification and properties of DNA polymerase from Bacillus licheniformis and Bacillus stearothermophilus. Biochim Biophys Acta. 1972; 272:156-66.

61. Golovacheva RS, Loginova LG, Salikhov TA, Kolesnikov AA, Zaitseva GN. New thermophilic species, Bacillus thermocatenulatus nov. sp. Microbiology. 1975; 44:230-3. 
62. Sunna A, Tokajian S, Burghardt J, Rainey F, Antranikian G, Hashwa F. Identification of Bacillus kaustophilus, Bacillus thermocatenulatus and Bacillus strain HSR as members of Bacillus thermoleovorans. Syst Appl Microbiol. 1997:20:232-7.

63. Huson DH, Bryant D. Application of phylogenetic networks in evolutionary studies. Mol Biol Evol. 2006:23:254-267.58.

64. Richter M, Rossello-Mora R. Shifting the genomic gold standard for the prokaryotic species definition. Proc Natl Acad Sci U S A. 2009;106:19126-31.

65. Goh KM, Gan HM, Chan K-G, Chan GF, Shahar S, Chong CS, et al. Chai KP: Analysis of Anoxybacillus genomes from the aspects of lifestyle adaptations, prophage diversity, and carbohydrate metabolism. PLoS One. 2014:9(3). doi: 10.1371/journal.pone.0090549.

66. Sun ZH, Harris HMB, McCann A, Guo CY, Argimon S, Zhang WY, et al. Expanding the biotechnology potential of lactobacilli through comparative genomics of 213 strains and associated genera. Nat Commun. 2015; doi:10. 1038/ncomms9322.

67. Wiedenbeck J, Cohan FM. Origins of bacterial diversity through horizontal genetic transfer and adaptation to new ecological niches. FEMS Microbiol Rev. 2011;35:957-76.

68. Vandamme P, Peeters C. Time to revisit polyphasic taxonomy. Anton Leeuw Int J Gen Mol Microbiol. 2014;106:57-65.

69. Claus D, Berkeley RCW. Genus Bacillus Cohn 1872. In: Sneath PHA, Mair NS, Sharpe ME, Holt JG, editors. Bergey's Manual of Systematic Bacteriology. 1986;2:1105-39.

70. Logan NA, De Vos P. Dinsdale AE genus Geobacillus. In: De Vos P, Garrity GM, Jones D, Krieg NR, Ludwig W, Rainey FA, Schleifer KH, Whitman WB, editors. Bergey's manual of systematic bacteriology, vol. 3. 2nd ed. New York, USA: Springer; 2009. p. 144-60.

71. Zeigler DR. The Geobacillus paradox: why is a thermophilic bacterial genus so prevalent on a mesophilic planet? Microbiology. 2014;160:1-11.

72. Rasko DA, Altherr MR, Han CS, Ravel J. Genomics of the Bacillus cereus group of organisms. FEMS Microbiol Rev. 2005;29:303-29.

73. Bezuidt OKI, Makhalanyane TP, Gomri MA, Kharroub K, Cowan DA. Draft genome sequence of thermophilic Geobacillus sp. strain Sah69, isolated from Saharan soil, Southeast Algeria. Genome Announc. 2015; doi:10.1128/ genomeA.01447-15.

74. Blanchard K, Robic S, Matsumura I. Transformable facultative thermophile Geobacillus stearothermophilus NUB321 as a host strain for metabolic engineering. Appl Microbiol Biotechnol. 2014;98:6715-23.

75. Brumm P, Land ML, Hauser LJ, Jeffries CD, Chang YJ, Mead DA. Complete genome sequences of Geobacillus sp Y412MC52, a xylan-degrading strain isolated from obsidian hot spring in Yellowstone national park. Stand Genomic Sci. 2015; doi:10.1186/s40793-015-0075-0.

76. Brumm PJ, De Maayer P, Mead DA, Cowan DA. Genomic analysis of six new Geobacillus strains reveals highly conserved carbohydrate degradation architectures and strategies. Front Microbiol. 2015; doi:10. 3389/fmicb.2015.00430.

77. De Maayer P, Williamson CE, Vennard CT, Danson MJ, Cowan DA. Draft genome sequences of Geobacillus sp. strains CAMR5420 and CAMR12739. Genome Announc. 2014; doi:10.1128/genomeA.00567-14.

78. Ortiz EM, Berretta MF, Navas LE, Benintende GB, Amadio AF, Zandomeni RO. Draft Genome Sequence of Geobacillus sp. Isolate T6, a thermophilic bacterium collected from a thermal spring in Argentina. Genome Announc. 2015; doi:10.1128/genomeA.00743-15.

79. Petkauskaite R, Blom J, Goesmann A, Kuisiene N. Draft genome sequence of pectic polysaccharide-degrading moderate thermophilic bacterium Geobacillus thermodenitrificans DSM 101594. Braz J Microbiol. 2017:48:7-8.

80. Pore SD, Arora P, Dhakephalkar PK. Draft genome sequence of Geobacillus sp. strain FW23, isolated from a formation water sample. Genome Announc. 2014; doi:10.1128/genomeA.00352-14.

81. Rozonov AS, Logacheva MD, Peltek SE. Draft genome sequences of Geobacillus stearothermophilus strains 22 and 53 isolated from the Garga hot spring in the Barguzin River valley of the Russian Federation. Genome Announc. 2014; doi:10.1128/genomeA.01205-14.

82. Sakaff MKLM, Rahman AYA, Saito JA, Hou S, Alam M. Complete genome sequence of the thermophilic bacterium Geobacillus thermoleovorans CCB_ US3_UF5. J Bacteriol2012;194:1239-1239.

83. Shintani M, Ohtsubo Y, Fukuda K, Hosoyama A, Ohji S, Yamazoe A, et al. Complete genome sequence of the thermophilic polychlorinated biphenyl degrader Geobacillus sp. strain JF8 (NBRC 109937). Genome Announc. 2014; doi:10.1128/genomeA.01213-13.
84. Siddiqui M, Rashid N, Ayyampalayam S, Whitman WB. Draft genome sequence of Geobacillus thermopakistaniensis strain MAS1. Genome Announc. 2014; doi:10.1128/genomeA.00559-1.

85. Takami H, Nishi S, Lu J, Shinamura S, Takaki Y. Genomic characterization of thermophilic Geobacillus species isolated from the deepest sea mud of the Mariana trench. Extremophiles. 2004;8:351-6.

86. Wissuwa J, Stokke R, Fedøy A-E, Lian K, Smalås AO, Steen IH. Isolation and complete genome sequence of the thermophilic Geobacillus sp. 12AMOR1 from an Arctic deep-sea hydrothermal vent site. Standards in genomic. Sciences. 2016;11:16

87. Zhao Y, Caspers MP, Abee T, Siezen RJ, Kort R. Complete genome sequence of Geobacillus thermoglucosidans TNO-09.020, a thermophilic sporeformer associated with a dairy-processing environment. J Bacterio 2012;194:4118-4118.

88. Zheng B, Zhang F, Chai L, Yu G, Shu F, Wang Z, et al. Permanent draft genome sequence of Geobacillus thermocatenulatus strain GS-1. Marine Genom. 2014;18:129-31.

89. Seemann T. Prokka: rapid prokaryotic genome annotation. Bioinformatics. 2014:30:2068-9.

90. Li L, Stoeckert CJ, Roos DS. OrthoMCL: identification of ortholog groups for eukaryotic genomes. Genome Res. 2003;13:2178-89.

91. Biggs PJ, Fearnhead P, Hotter G, Mohan V, Collins-Emerson J, Kwan E, et al. Whole-genome comparison of two Campylobacter jejuni isolates of the same sequence type reveals multiple loci of different ancestral lineage. PLoS One. 2011; doi:10.1371/journal.pone.0027121.

92. Edgar RC. MUSCLE: multiple sequence alignment with high accuracy and high throughput. Nucleic Acids Res. 2004;32:1792-7.

93. Bryant D, Moulton V. Neighbor-net: an agglomerative method for the construction of phylogenetic networks. Mol Biol Evol. 2004;21:255-65.

94. Harrigan WF Examination of cultures for motility by 'Hanging Drop' preparations. In: Harrigan WF, editor. Laboratory Methods in Food Microbiology. 3rd ed. San Diego, California, USA: Academic Press; 1998: 39-40.

95. Baldock JD. Heat resistance of rough and smooth variants of Bacillus stearothermophilus. Dissertation Abstracts International Section B The Sciences and Engineering. 1970;30:5088-9.

96. Humbert RD, Deguzman AN, Fields ML. Studies on variants of Bacillus stearothermophilus strain NCA 1518. Appl Microbiol. 1972;23:693-8.

97. Jung L, Jost R, Stoll E, Zuber H. Metabolic differences in Bacillus stearothermophilus grown at 55 degrees $C$ and 37 degrees $C$. Arch Microbiol. 1974;95:125-38

98. Walker PD. Wolf J taxonomy of Bacillus stearothermophilus. In: Barker AN, editor. Spore research. London and New York: Academic Press; 1971. p. 247-62.

99. Logan NA, Berkeley RCW. Identification of Bacillus strains using the API system. J Gen Microbiol. 1984;130:1871-82.

\section{Submit your next manuscript to BioMed Central and we will help you at every step:}

- We accept pre-submission inquiries

- Our selector tool helps you to find the most relevant journal

- We provide round the clock customer support

- Convenient online submission

- Thorough peer review

- Inclusion in PubMed and all major indexing services

- Maximum visibility for your research

Submit your manuscript at www.biomedcentral.com/submit 